\title{
A botanical product containing cistanche and ginkgo extracts improves chronic fatigue syndrome: a randomized, double-blind, placebo-controlled study
}

Juntao Kan ( $\sim$ Junot.Kan@Amway.com )

Nutrilite Health Institute https://orcid.org/0000-0001-7280-6394

Chun $\mathrm{Hu}$

Nutrilite Health Institute

Liang Chen

Nutrilite Health Institute

Siyu Liu

Nutrilite Health Institute

Dawna Venzon

Nutrilite Health Institute

Mary Murray

Nutrilite Health Institute

Chaojih Wang

Sinphar

Ailing Yeh

Sinphar

Bryan Liu

East China University of Science and Technology

Shuguang Li ( $\sim$ leeshuguang@fudan.edu.cn )

Fudan University

Jun Du ( $\nabla$ eric.du@amway.com )

Nutrilite Health Institute

\section{Research}

Keywords: chronic fatigue syndrome, cistanche, ginkgo, Chalder fatigue questionnaire, quality of life, sexual life quality, blood lactic acid

Posted Date: September 3rd, 2020 
DOI: https://doi.org/10.21203/rs.3.rs-64733/v1

License: (c) (i) This work is licensed under a Creative Commons Attribution 4.0 International License. Read Full License 


\section{Abstract}

\section{Background}

Dietary therapy may be beneficial in alleviating symptoms of chronic fatigue syndrome (CFS), a disorder characterized by extreme fatigue with no underlying medical condition. The aim of this study is to evaluate the protective effect of a botanical product containing cistanche (Cistanche tubulosa (Schenk) Wight) and ginkgo (Ginkgo biloba L.) extracts on adults with CFS in a randomized, double-blind, placebocontrolled clinical trial.

\section{Methods}

A total of 190 subjects with CFS were randomized to receive low dose, high dose of product or placebo (tablets) once daily for 60 days. Blood samples and questionnaires of Chalder fatigue, quality of life (QOL), and sexual life quality (SLQ) were collected at baseline and post-intervention.

\section{Results}

Our product significantly relieved the symptoms of CFS, among which impaired memory or concentration, muscle pain, unrefreshing sleep, and post-exertional malaise were significantly improved. The intervention of product significantly decreased both physical and mental fatigue scores of the Chalder fatigue questionnaire, and improved QOL and SLQ of the subjects. Levels of blood ammonia and lactic acid in the subjects of product group were significantly lower than those of placebo group. In addition, the change in lactic acid concentration was significantly associated with the effectiveness for CFS symptoms, and correlated to the change in total physical fatigue score of the Chalder fatigue questionnaire.

\section{Conclusions}

Our botanical product relieves the CFS symptoms and improves the scores of Chalder fatigue, QOL and SLQ questionnaires. These findings suggest a nutritional supplementation approach with botanical extracts as an alternative strategy in mitigating CFS.

Trial registration

This trial has been registered on https://clinicaltrials.gov/ under the identification code: NCT02807649. Registered 21 June 2016 - Retrospectively registered.

\section{Background}

Chronic fatigue syndrome (CFS) is the common name for a group of significantly debilitating medical conditions characterized by persistent fatigue and other specific symptoms that last for a minimum of six months in adults [1]. Symptoms of CFS include post-exertional malaise, unrefreshing sleep, impaired 
memory or concentration, muscle pain, polyarthralgia, sore throat, tender lymph nodes, or new headaches [2]. Its global prevalence, estimated between $0.4 \%$ and $2.5 \%$, is growing [3]. The cause of CFS is still unclear but appears to result from multiple factors. Generally, the onset of CFS is associated with psychological stress, endocrine and immune disorder, genetic factors, and viral infections [1]. Currently, there is no standard treatment for CFS. Commonly used treatments include the medications which enhance immunity system and nutrition-balanced therapy, cognitive behavioral therapy, local physiotherapy, and graded exercise therapy [4]. The main purposes of the treatments are to relieve CFS symptoms, improve the psychological condition and social behavioral function.

CFS patients report a high use of nutritional supplements and approximately half of the patients benefit from nutritional intervention [5]. Therefore, dietary therapy, including diet modification or dietary supplementation, may be beneficial in alleviating symptoms and reducing fatigue in CFS [6]. Ginkgo (Ginkgo biloba L.) and cistanche (Cistanche tubulosa (Schenk) Wight) are two popularly used dietary supplements in China's thousands of years of history. As a Yang-invigorating tonic herb of traditional Chinese medicine (TCM), cistanche has been proved to be beneficial in the treatment of CFS in subjects with Yang deficiency through enhancing mitochondrial function [7]. Ginkgo is a powerful antioxidant and can improve cerebral perfusion and associated memory and cognitive deficits [6].

We previously developed a botanical product containing the extracts of cistanche and ginkgo and proved the health claim of improving memory in healthy subjects $[8,9]$. In this randomized, double-blind, placebocontrolled study, we tried to test the protective effect of the product in subjects with CFS.

\section{Methods}

\section{Trial design}

This randomized, double-blind, placebo-controlled clinical trial was conducted in Community Hospital of Baoshan District, Shanghai, China. The subjects were identified from a hospital-owned database. A total of 190 subjects were initially enrolled in the study at baseline, and stratified by age and genders, either 1) males aged 35-50 years old, females aged 35-40 years old or 2) males aged 51-60 years old, females aged 41-60 years old. The subjects were randomly assigned to 3 groups (group 1: placebo; group 2: low dose of the product; group 3: high dose of the product). The subjects consumed their designated products once daily for 60 days. During the study, 15 subjects withdrew, leaving 175 subjects in the per protocol (PP) analysis (Fig. 1). The total dropout rate was 7.9\%. Blood samples and questionnaires of Chalder fatigue, quality of life (QOL), and sexual life quality (SLQ) were collected at baseline and postintervention (day 60). Informed consent was obtained from all subjects. This study was approved by the Institutional Review Board (IRB) of Shanghai Nutrition Society and registered at ClinicalTrials.gov (NCT02807649).

\section{Intervention}


The test products were tablets containing cistanche extract (300 mg for low dose group, $450 \mathrm{mg}$ for high dose group; standardized with 7.55\% echinacoside) and ginkgo extract (120 mg for low dose group, $180 \mathrm{mg}$ for high dose group; standardized with $2.85 \%$ total flavanol glycosides). All the test products and placebo were manufactured in a Good Manufacturing Practice pilot plant (Nutrilite) under quality assurance considering the presence of microorganisms, heavy metals, and pesticide residue.

\section{Inclusion/exclusion criteria}

The inclusion criteria were as follows: $35-60$ years old male or female volunteers, who were diagnosed as CFS by study physician. More details on the assessment of CFS are provided in the following section. Subjects were excluded if their body mass index was $\geq 28$; they had flu/symptoms of viral infections within three months before the first visit to the site; had history of or be diagnosed of any of the following diseases that might affect the study results: gastrointestinal disorders, skeletal muscle dysfunction, hepatopathy, nephropathy, endocrine disease, blood disorders, respiratory and cardiovascular diseases; were currently taking medicine for cardiovascular or metabolic disease; were current smoker; were current or previous alcohol abuser; were pregnant or lactating; were currently having or had any medical or nutritious therapies, including taking protein supplements or nutrients that promoted exercise capacity within 3 months before screening; had lost or gained weight over 5 kilograms within 3 months before screening; had hospitalizations within 3 months before screening; had participated in similar clinical trials within 6 months before screening; or were not willing to comply with the study procedures.

\section{CFS assessment}

The CFS was assessed at the enrollment in accordance with the diagnosis criteria published by U.S. Centers for Disease Control (CDC) [2]. It was diagnosed as CFS when 1) the continuous or recurrent attacks of unexplained severe fatigue lasted for more than 6 months and it could not be alleviated after sufficient rest, resulting in substantial reduction in previous levels of occupational, educational, social, or personal activities; 2) Four or more of the following symptoms were concurrently present for over 6 months: impaired memory or concentration; sore throat; tender cervical or axillary lymph nodes; muscle pain; multiple joint pain; new headaches; unrefreshing sleep; and post-exertional malaise. After the intervention, each of above symptoms was assessed again for evaluation of the product efficacy. The overall effective evaluation was based on the sum of cured cases (all symptoms were relieved) and relived cases (some symptoms were relieved).

\section{Chalder fatigue questionnaire}

The Chalder fatigue questionnaire has been widely used to measure the extent and severity of physical and mental fatigue in clinical and epidemiological populations. The original Chalder fatigue scale consisted of 14 items designed to measure fatigue severity over the past 3 months [10]. In the following studies, 3 items were dropped from the 14-item version, resulting in a revised 11-item version [11]. For the 11 items, there are two subscales to evaluate two types of fatigue: physical and mental. The score was rated on a four-point Likert scale $(0=$ not at all; 1 = the same as usual; $2=$ more than usual; $3=$ much more than usual). Higher score indicates a greater fatigue. 


\section{QOL questionnaire}

The QOL was assessed using a modified World Health Organization (WHO) QOL questionnaire $[12,13]$. The questionnaire comprises 26 items, providing an integrated measurement of individual's QOL based on the following factors: physical health (PHYS), psychological health (PSYCH), social relationships (SOCIL), living environment (ENVIR), and subjects' self-evaluation of their QOL and health status (Q1 and Q2). Each item in the questionnaire provides a score ranging from 1 to 5 . The scores of Q3, Q4 and Q26 were taken inversely (the new score is the difference between 6 and the original score) since the higher original scores were associated with lower QOL. The formula of QOL score calculation was listed as follows: $\mathrm{PHYS}=4 \times[(6-\mathrm{Q} 3)+(6-\mathrm{Q} 4)+\mathrm{Q} 10+\mathrm{Q} 15+\mathrm{Q} 16+\mathrm{Q} 17+\mathrm{Q} 18] / 7 ; \mathrm{PSYCH}=4 \times[\mathrm{Q} 5+\mathrm{Q} 6+\mathrm{Q} 7+\mathrm{Q} 11+$ $\mathrm{Q} 19+(6-\mathrm{Q} 26)] / 6 ; \mathrm{SOCIL}=4 \times(\mathrm{Q} 20+\mathrm{Q} 21+\mathrm{Q} 22) / 3 ; \mathrm{ENVIR}=4 \times(\mathrm{Q} 8+\mathrm{Q} 9+\mathrm{Q} 12+\mathrm{Q} 13+\mathrm{Q} 14+\mathrm{Q} 23+\mathrm{Q} 24+$ Q25)/8; QOL score = (Q1 + Q2 + PHYS + PSYCH + SOCIL + ENVIR-4) $\times(100 / 16)$.

\section{SLQ questionnaire}

The SLQ questionnaire was previously developed to evaluate the quality of sexual life of the subjects [14]. The original 10 item scores (ranging from -4 to +4 in value) were converted to a 0 to 8 scale score by adding 4 to each recorded response. The 0 to 8 scale score was converted to a standardized score by dividing that score by 8 and multiplying the result by 100 . The SLQ scale score for a respondent was computed as the mean of the 10 standardized item scores.

\section{Biochemical analysis}

Blood ammonia, glucose, free fatty acid, creatine kinase, C-reactive protein, lactic acid, estradiol (only for female), and testosterone (only for male) were determined using commercially available kits according to the manufacture's instruction (Jiancheng, Nanjing, China).

\section{Sample size calculation}

Sample size was chosen based on a significant level of 0.016 ( 0.05 after adjustment for three multiple comparisons), $80 \%$ power and expected proportion of responders of 0.5 and 0.8 for placebo and intervention groups, respectively. Sixty-three participants for each group was to give 53 completed participants with accounting for $15 \%$ dropout rate. A total number of 190 subjects were enrolled to ensure at least 159 subjects in completing the study.

\section{Statistical analysis}

Statistical analyses were completed using SAS 9.4 (SAS Institute Inc, Cary, NC, USA). All statistical tests of our hypothesis were 2-sided and performed at the 0.05 significance level. Means and standard deviations were summarized for normally distributed continuous variables, medians were provided for non-normal variables, and frequencies and percentages were provided for categorical variables. Evaluations of product effect were performed using chi-square test or analysis of covariance (ANCOVA) followed by pair-wise group comparison for the variables with significant group difference. 


\section{Results}

\section{Characteristics of subjects}

Summary statistics of baseline subject characteristics were shown in Table 1. No group difference was observed at baseline among groups in demographic data, including gender, age, body weight, height, body mass index, body temperature, and blood pressure.

\section{CFS assessment}

The frequency and percent of subjects with cured or relieved CFS, as well as the total effective cases after 60 days of product intervention were shown in Table 2. Nine (15.5\%) subjects with CFS were cured in low dose group, $11(18.6 \%)$ in high dose group, while $0 \%$ in placebo group. Some of the symptoms were relieved in 33 (56.9\%), 37 (62.7\%) and 16 (27.6\%) subjects in low dose, high dose, and placebo group, respectively. These resulted in an overall effectiveness of $72.4 \%$ in low dose group and $81.4 \%$ in high dose group ( $P<0.001$ compared to $27.6 \%$ in the placebo group). Among all 8 individual symptoms, impaired memory or concentration, muscle pain, unrefreshing sleep, and post-exertional malaise were significantly $(P<0.001)$ relieved in the subjects of low dose and high dose group compared to those in the placebo group after product intervention (Supplementary Table 1).

\section{Chalder fatigue questionnaire}

The score of each question in the 11 item-Chalder fatigue questionnaire and the total physical and mental fatigue scores were summarized in Table 3. After 60 days of product intervention, both low dose and high dose groups had significantly lower fatigue scores compared to the placebo group for all physical and mental fatigue questions $(P<0.001)$. Significant difference was also observed for low dose group versus high dose group in total physical fatigue score $(P<0.01)$ and Q3-sleepy or drowsy feeling score $(P<0.01)$, suggesting superior effect of high dose of the product.

\section{QOL and SLQ questionnaires}

The individual and area (PHYS, PSYCH, SOCIL, ENVIR) scores of the QOL questionnaire were shown in Table 4. After 60 days of product intervention, significant group difference was observed in Q1-overall rating of quality of life, Q2-overall satisfaction of health; Q3, 10, 16 and 17 under the PHYS area, as well as the area score; Q7 and 26 under the PSYCH area; and Q21 under the SOCIL area.

The individual and scale score of the SLQ questionnaire with stratification of gender were shown in Table 5. For male subjects, there were significant group difference in all 10 items and scale score after the product intervention. For female subjects, significant group difference was observed in all items except ease of insertion and partner's overall pleasure of lovemaking. 


\section{Blood biomarkers}

The concentrations of blood biomarkers were comparable at baseline (Table 6). After the product intervention, both low dose group and high dose group had significantly lower blood ammonia $(P<0.01$ and $P<0.05$, respectively) and blood lactic acid concentration $(P<0.05$ and $P<0.01$, respectively) than the placebo group. The intervention of product led to a trend of increase in testosterone, although the difference did not reach statistical significance $(P=0.0743)$.

Logistic regression was used to evaluate the effect of the change in blood biomarkers on the cure and relief of CFS symptoms (overall effectiveness). The results were shown in Table 7. The change in blood glucose and lactic acid concentration were significantly associated with the effectiveness for CFS symptoms in both univariate analysis ( $P=0.0058$ and 0.0061 , respectively) and multivariate analysis ( $P$ $=0.0075$ and 0.0108 , respectively). Pearson correlation coefficient and significance test were further used to evaluate the correlation between the changes of blood biomarkers and the changes of the Chadler fatigue questionnaire scores (Supplementary Table 2). The change in blood lactic acid concentration was significantly correlated to the total physical fatigue score $(R=0.1639, P=0.0302)$, Q1-problems of tiredness $(R=0.1886, P=0.0166)$, and Q2-need to rest more $(R=0.2254, P=0.0027)$.

\section{Discussion}

The etiology of CFS is still unknown, therefore, the diagnosis of CFS is made in accordance with symptom-specific criteria [5]. The CDC criteria (1994) is now the most frequently used case definition for CFS [2]. In the current study, we followed the CDC criteria to enroll CFS subjects, and after the intervention of our product, there was significantly higher effective (cure and relief) rate in the product group compared to the placebo. Among all 8 mentioned symptoms in the CDC criteria, impaired memory or concentration, muscle pain, unrefreshing sleep, and post-exertional malaise were significantly relieved in the subjects consuming our product. In order to quantitively measure the fatigue, many questionnaires, such as Chalder fatigue questionnaire, checklist individual strength, fatigue severity scale, multidimensional fatigue inventory, and fatigue index symptom, were reported previously [15]. Among them, Chalder fatigue questionnaire is the most intensively used $[10,11]$. By using the Chalder fatigue questionnaire, we observed significantly improved physical and mental fatigue scores in the product group after the intervention.

QOL is an important outcome evaluated in the CFS research [5]. In the currently used WHO-QOL questionnaire, 26 items are divided into four sections, PHYS, PSYCH, SOCIL, ENVIR [12, 13]. Our product could improve 4 items (Q3, 10, 16, and 17) in PHYS, 2 items (Q7 and 26) in PSYCH, 1 item (Q21) in SOCIL, but no item in ENVIR. Among all the items, Q3 was related to muscle pain, Q7 was related to impaired memory or concentration, and Q16 was related to unrefreshing sleep. These data were consistent with those from the CFS assessment. Poor sleep quality was widely reported in patients with CFS [16], and nocturia was associated with poor sleep quality $[17,18]$. In our study, we observed a significantly $(P<$ $0.01)$ improved frequency of nocturia in the subjects of the product group (data not shown). The 
beneficial effect of our product on the nocturia mainly contributed to the cistanche, a well-known kidney yang-tonifying herb of TCM $[7,19]$. Improving memory is the original health claim of our product $[8,9]$. In the current study, we confirmed the beneficial effect on the memory and concentration, which largely depended on the ginkgo $[20,21]$. Muscle pain was another improved symptom in this study, and it was the first report to show the protective effect of cistanche and ginkgo on the muscle pain.

Considering the kidney yang-tonifying effect of cistanche, and kidney is a critical organ related with sexual function from the TCM perspective [22], we additionally collected SLQ questionnaire in the current study. Different from the male subjects who achieved all items improved, female subjects failed 2 items, which were ease of insertion and partner's overall pleasure of lovemaking. These interesting results suggested that our product was possibly more effective for men, especially the erectile function. We further determined the sexual hormones and observed a trend of increase in testosterone after the intervention, instead, no significance was found in estradiol. These data were consistent with abundant of previously reported in vivo data, which showed that the cistanche extract increased testosterone level and improved reproductive dysfunction in rats [23-26]. No report about the effect of cistanche on estradiol for now.

Lactic acid is formed and accumulated in muscle under the condition of high energy demand and insufficient oxygen supply [27]. The accumulation of lactic acid is very common in both CFS patients and animals $[28,29]$. It was previously reported that cistanche and ginkgo extracts could reduce the blood lactic acid level in mice and rats [30,31]. In our RCT, we also observed a significant decrease of blood lactic acid level in the product group. Furthermore, the change in lactic acid concentration was significantly associated with the effectiveness for CFS symptoms in both univariate analysis and multivariate analysis. Pearson correlation coefficient and significance test also showed that the change in lactic acid concentration was significantly correlated to that in total physical fatigue score of the Chalder fatigue questionnaire. All data suggested that blood lactic acid could be a potential biomarker to predict the prognosis of CFS.

The limitation of is the study is the deterministic nature of formula research, making it difficult to attribute beneficial effects on CFS to any specific constituent, therefore, we cannot estimate the additional improvement that the combination provided over cistanche or ginkgo alone. In addition, the assessment of CFS and life quality was performed by subjective questionnaires, instead of objective tests, which will be needed to confirm the conclusion in the future study.

\section{Conclusions}

We carried out a randomized, double-blind, placebo-controlled study using a botanical product containing cistanche and ginkgo extracts, and demonstrated that the product could relieve the symptoms of CFS, as well as improve the scores of Chalder fatigue, QOL and SLQ questionnaires. These findings suggest a nutritional supplementation approach with botanical extracts as an alternative strategy in mitigating CFS. 


\section{Abbreviations}

CFS, chronic fatigue syndrome; ENVIR, living environment; PHYS, physical health; PSYCH, psychological health; QOL, quality of life; SLQ, sexual life quality; SOCIL, social relationships; TCM, traditional Chinese medicine

\section{Declarations}

\section{Ethics approval and consent to participate}

The study was conducted according to the guidelines laid down in the 1964 Declaration of Helsinki and its later amendments. All procedures involving human subjects were reviewed and approved by the IRB of Shanghai Nutrition Society. Written informed consent was obtained from all participants.

\section{Consent for publication}

Not applicable.

\section{Availability of data and materials}

The datasets supporting the conclusions of this article are included within the article.

\section{Competing interests}

The authors declare that they have no competing interests.

\section{Funding}

Not applicable.

\section{Authors' contributions}

SL and JD designed research; $\mathrm{CH}, \mathrm{DV}$ and MM conducted research; $\mathrm{CW}$ and AY provided resources; JK and $\mathrm{BL}$ analyzed data; $\mathrm{LC}$ and SL validated the analysis; JK and $\mathrm{CH}$ wrote the paper; JD had primary responsibility for final content. All authors read and approved the final manuscript.

\section{Acknowledgements}

We thank Li Zhang and his colleagues from SPRIM China for their great work in coordinating the clinical trial. We also thank Sinphar Tianli pharmaceuticals to provide the raw materials of the test product.

\section{References}

1. Yancey JR, Thomas SM. Chronic fatigue syndrome: diagnosis and treatment. Am Fam Physician. 2012;86(8):741-6. 
2. Fukuda K, Straus SE, Hickie I, Sharpe MC, Dobbins JG, Komaroff A. The chronic fatigue syndrome: a comprehensive approach to its definition and study. International Chronic Fatigue Syndrome Study Group. Ann Intern Med. 1994;121(12):953-9.

3. Słomko J, Newton JL, Kujawski S, Tafil-Klawe M, Klawe J, Staines D, Marshall-Gradisnik S, Zalewski P. Prevalence and characteristics of chronic fatigue syndrome/myalgic encephalomyelitis (CFS/ME) in Poland: a cross-sectional study. BMJ Open. 2019;9(3):e023955.

4. Bested AC, Marshall LM. Review of Myalgic Encephalomyelitis/Chronic Fatigue Syndrome: an evidence-based approach to diagnosis and management by clinicians. Rev Environ Health. 2015;30(4):223-49.

5. Campagnolo N, Johnston S, Collatz A, Staines D, Marshall-Gradisnik S. Dietary and nutrition interventions for the therapeutic treatment of chronic fatigue syndrome/myalgic encephalomyelitis: a systematic review. J Hum Nutr Diet. 2017;30(3):247-59.

6. Logan AC, Wong C. Chronic fatigue syndrome: oxidative stress and dietary modifications. Altern Med Rev. 2001;6(5):450-9.

7. Leong PK, Wong HS, Chen J, Ko KM. Yang/Qi invigoration: an herbal therapy for chronic fatigue syndrome with yang deficiency? Evid Based Complement Alternat Med. 2015;2015:945901.

8. Salter VDS. A MM: A composition comprising cistanche and ginkgo extracts, the composition useful for improving memory of a subject. In.; 2016.

9. Venzon DSS, Murray MA. Method for improving memory of a subject using a composition comprising cistanche and ginkgo extracts. In.; 2015.

10. Chalder T, Berelowitz G, Pawlikowska T, Watts L, Wessely S, Wright D, Wallace EP. Development of a fatigue scale. J Psychosom Res. 1993;37(2):147-53.

11. Cella M, Chalder T. Measuring fatigue in clinical and community settings. J Psychosom Res. 2010;69(1):17-22.

12. Kan J, Cheng J, Xu L, Hood M, Zhong D, Cheng M, Liu Y, Chen L, Du J. The combination of wheat peptides and fucoidan protects against chronic superficial gastritis and alters gut microbiota: a double-blinded, placebo-controlled study. Eur J Nutr. 2020;59(4):1655-66.

13. TW G: The World Health Organization Quality of Life assessment (WHOQOL): position paper from the World Health Organization. Soc Sci Med 1995, 41(10):1403-1409.

14. Woodward JM, Hass SL, Woodward PJ. Reliability and validity of the sexual life quality questionnaire (SLQQ). Qual Life Res. 2002;11(4):365-77.

15. Hewlett S, Dures E, Almeida C. Measures of fatigue. Arthritis Care Res (Hoboken). 2011;63(Suppl 11):263-86.

16. Castro-Marrero J, Zaragozá MC, González-Garcia S, Aliste L, Sáez-Francàs N, Romero O, Ferré A, Fernández de Sevilla T, Alegre J. Poor self-reported sleep quality and health-related quality of life in patients with chronic fatigue syndrome/myalgic encephalomyelitis. J Sleep Res. 2018;27(6):e12703. 
17. Fung $\mathrm{CH}$, Vaughan $\mathrm{CP}$, Markland $\mathrm{AD}$, Huang AJ, Mitchell MN, Bliwise DL, Ancoli-Israel S, Redline S, Alessi CA, Stone K. Nocturia is Associated with Poor Sleep Quality Among Older Women in the Study of Osteoporotic Fractures. J Am Geriatr Soc. 2017;65(11):2502-9.

18. Choi EPH, Wan EYF, Kwok JYY, Chin WY, Lam CLK. The mediating role of sleep quality in the association between nocturia and health-related quality of life. Health Qual Life Outcomes. 2019;17(1):181.

19. Fu Z, Fan X, Wang X, Gao X. Cistanches Herba: An overview of its chemistry, pharmacology, and pharmacokinetics property. J Ethnopharmacol. 2018;219:233-47.

20. Palta P, Carlson MC, Crum RM, Colantuoni E, Sharrett AR, Yasar S, Nahin RL, Dekosky ST, Snitz B, Lopez O, et al. Diabetes and Cognitive Decline in Older Adults: The Ginkgo Evaluation of Memory Study. J Gerontol A Biol Sci Med Sci. 2017;73(1):123-30.

21. Field BH, Vadnal R. Ginkgo biloba and Memory: An Overview. Nutr Neurosci. 1998;1(4):255-67.

22. Li H, Jiang H, Liu J. Traditional Chinese medical therapy for erectile dysfunction. Transl Androl Urol. 2017;6(2):192-8.

23. Kong ZL, Johnson A, Ko FC, He JL, Cheng SC: Effect of Cistanche Tubulosa Extracts on Male Reproductive Function in Streptozotocinâđ» Nicotinamide-Induced Diabetic Rats. Nutrients 2018, 10(10).

24. Wang T, Chen C, Yang M, Deng B, Kirby GM, Zhang X. Cistanche tubulosa ethanol extract mediates rat sex hormone levels by induction of testicular steroidgenic enzymes. Pharm Biol. 2016;54(3):4817.

25. Jiang Z, Wang J, Li X, Zhang X. Echinacoside and Cistanche tubulosa (Schenk) R. wight ameliorate bisphenol A-induced testicular and sperm damage in rats through gonad axis regulated steroidogenic enzymes. J Ethnopharmacol. 2016;193:321-8.

26. Wang Q, Dong J, Lu W, He H, Sun X, Zhang K, Song Q, Jiang Y, Wang Y, Li C, et al. Phenylethanol glycosides from Cistanche tubulosa improved reproductive dysfunction by regulating testicular steroids through CYP450-3ß-HSD pathway. J Ethnopharmacol. 2020;251:112500.

27. Sahlin K. Muscle fatigue and lactic acid accumulation. Acta Physiol Scand Suppl. 1986;556:83-91.

28. Jammes Y, Steinberg JG, Mambrini O, Brégeon F, Delliaux S. Chronic fatigue syndrome: assessment of increased oxidative stress and altered muscle excitability in response to incremental exercise. $J$ Intern Med. 2005;257(3):299-310.

29. Wang X, Qu Y, Zhang Y, Li S, Sun Y, Chen Z, Teng L, Wang D. Antifatigue Potential Activity of Sarcodon imbricatus in Acute Excise-Treated and Chronic Fatigue Syndrome in Mice via Regulation of Nrf2-Mediated Oxidative Stress. Oxid Med Cell Longev. 2018;2018:9140896.

30. Cai RL, Yang MH, Shi Y, Chen J, Li YC, Qi Y. Antifatigue activity of phenylethanoid-rich extract from Cistanche deserticola. Phytother Res. 2010;24(2):313-5.

31. Li H, Qiu P, Wang J, Niu C, Pan S. Effects of compound Ginkgo biloba on intestinal permeability in rats with alcohol-induced liver injury. Food Funct. 2015;6(2):470-8. 


\section{Tables}

Table 1. Baseline characteristics of subjects who completed the study

\begin{tabular}{lllll}
\hline Baseline Characteristics & $\begin{array}{l}\text { Placebo } \\
(\mathrm{n}=58)\end{array}$ & $\begin{array}{l}\text { Low dose } \\
(\mathrm{n}=58)\end{array}$ & $\begin{array}{l}\text { High dose } \\
(\mathrm{n}=59)\end{array}$ & $p$-value \\
\hline Female & $29(50.0 \%)$ & $31(53.4 \%)$ & $31(52.5 \%)$ & 0.928 \\
Gender and age strata & & & 5 & 0.894 \\
Female age 35-40 & 6 & 4 & 26 & N/A \\
Female age 41-60 & 23 & 27 & 6 & N/A \\
Male age 35-50 & 6 & 9 & 22 & N/A \\
Male age 51-60 & 23 & 18 & $50.5 \pm 7.0$ & 0.737 \\
Age (years) & $50.7 \pm 7.6$ & $51.5 \pm 7.5$ & $65.5 \pm 10.8$ & 0.741 \\
Weight $(\mathrm{kg})$ & $66.0 \pm 11.0$ & $64.6 \pm 9.0$ & $165.4 \pm 8.2$ & 0.553 \\
Height $(\mathrm{cm})$ & $166.4 \pm 7.4$ & $164.9 \pm 7.2$ & 165.4 & 0.963 \\
BMI $\left(\mathrm{kg} / \mathrm{m}^{2}\right)$ & $23.8 \pm 2.8$ & $23.7 \pm 2.6$ & $23.9 \pm 2.9$ & 0.715 \\
Body temperature $\left({ }^{\circ} \mathrm{C}\right)$ & $36.8 \pm 0.2$ & $36.8 \pm 0.2$ & $36.8 \pm 0.3$ & 0.687 \\
Systolic pressure $(\mathrm{mmHg})$ & $123.8 \pm 10.8$ & $123.1 \pm 14.4$ & $121.8 \pm 11.8$ & 0.200 \\
Diastolic pressure $(\mathrm{mmHg})$ & $76.5 \pm 6.1$ & $76.1 \pm 8.2$ & $74.0 \pm 9.2$ & 0.200 \\
\hline
\end{tabular}

Data are frequency (\%) or mean \pm standard deviation (SD). Group differences were evaluated using a chi-square test or one-way analysis of variance (ANOVA). N/A, not applicable.

Table 2. Summary of the change of symptoms of chronic fatigue syndrome (CFS)

\begin{tabular}{lcccc}
\hline & $\begin{array}{c}\text { Placebo } \\
(\mathrm{n}=58)\end{array}$ & $\begin{array}{c}\text { Low dose } \\
(\mathrm{n}=58)\end{array}$ & $\begin{array}{c}\text { High dose } \\
(\mathrm{n}=59)\end{array}$ & $\begin{array}{c}\text { Product effect } \\
p \text {-value }\end{array}$ \\
\hline Cure & $0(0.0 \%)$ & $9(15.5 \%)^{* *}$ & $11(18.6 \%)^{* *}$ & 0.0032 \\
Relief & $16(27.6 \%)$ & $33(56.9 \%)^{* *}$ & $37(62.7 \%)^{* * *}$ & 0.0004 \\
Effective (cure and relief) & $16(27.6 \%)$ & $42(72.4 \%)^{* * *}$ & $48(81.4 \%)^{* * *}$ & $<.0001$ \\
\hline
\end{tabular}

Data are frequency (\%). Product effect was evaluated by chi-square test. Post-hoc test with Bonferroni adjustment was applied to variables with significant group difference for further pair-wise group comparison. ${ }^{* *} P<0.01,{ }^{* * *} P<0.001$ compared with placebo group.

Table 3. Group differences in the scores of Chalder fatigue questionnaire 


\begin{tabular}{|c|c|c|c|c|c|c|c|}
\hline & \multicolumn{3}{|c|}{ Baseline } & \multicolumn{3}{|c|}{ Day 60} & \multirow{3}{*}{$\begin{array}{c}\text { Product } \\
\text { effect } \\
p \text {-value }\end{array}$} \\
\hline & \multirow[t]{2}{*}{$\begin{array}{l}\text { Placebo } \\
(\mathrm{n}=58)\end{array}$} & \multirow[t]{2}{*}{$\begin{array}{l}\text { Low dose } \\
\qquad(\mathrm{n}=58)\end{array}$} & \multirow{2}{*}{$\begin{array}{l}\text { High } \\
\text { dose } \\
(n=59)\end{array}$} & \multirow[t]{2}{*}{$\begin{array}{l}\text { Placebo } \\
(\mathrm{n}=58)\end{array}$} & \multirow[t]{2}{*}{$\begin{array}{l}\text { Low dose } \\
\qquad(\mathrm{n}=58)\end{array}$} & \multirow[t]{2}{*}{$\begin{array}{l}\text { High dose } \\
\qquad(\mathrm{n}=59)\end{array}$} & \\
\hline & & & & & & & \\
\hline Physical fatigue (total score): & $9.93 \pm 2.25$ & $9.78 \pm 1.86$ & $9.92 \pm 1.98$ & $9.64 \pm 1.61$ & $6.59 \pm 1.96^{* * *}$ & $5.61 \pm 2.39^{* * *, \# \#}$ & $<.0001$ \\
\hline 1. Do you have problems with tiredness? & $1.50 \pm 0.54$ & $1.53 \pm 0.57$ & $1.46 \pm 0.60$ & $1.45 \pm 0.50$ & $0.83 \pm 0.63^{* * *}$ & $0.66 \pm 0.58^{* * *}$ & $<.0001$ \\
\hline 2. Do you need to rest more? & $1.45 \pm 0.54$ & $1.47 \pm 0.57$ & $1.51 \pm 0.54$ & $1.36 \pm 0.55$ & $0.90 \pm 0.52^{* * *}$ & $0.75 \pm 0.54^{* * *}$ & $<.0001$ \\
\hline 3. Do you feel sleepy or drowsy? & $1.43 \pm 0.57$ & $1.45 \pm 0.50$ & $1.49 \pm 0.50$ & $1.38 \pm 0.64$ & $0.95 \pm 0.60^{* * *}$ & $0.66 \pm 0.58^{* * *, \# \#}$ & $<.0001$ \\
\hline 4. Do you have problems starting things? & $1.19 \pm 0.44$ & $1.10 \pm 0.31$ & $1.15 \pm 0.36$ & $1.22 \pm 0.50$ & $0.95 \pm 0.22^{* * *}$ & $0.93 \pm 0.31^{* * *}$ & $<.0001$ \\
\hline 5. Do you lack energy? & $1.41 \pm 0.56$ & $1.34 \pm 0.48$ & $1.37 \pm 0.49$ & $1.36 \pm 0.64$ & $0.91 \pm 0.47^{* * *}$ & $0.71 \pm 0.53^{* * *}$ & $<.0001$ \\
\hline $\begin{array}{l}\text { 6. Do you have less strength in your } \\
\text { muscles? }\end{array}$ & $1.57 \pm 0.53$ & $1.48 \pm 0.57$ & $1.53 \pm 0.63$ & $1.52 \pm 0.54$ & $1.19 \pm 0.48^{* * *}$ & $1.12 \pm 0.49^{* * *}$ & $<.0001$ \\
\hline 7. Do you feel weak? & $1.38 \pm 0.59$ & $1.40 \pm 0.49$ & $1.41 \pm 0.50$ & $1.34 \pm 0.55$ & $0.86 \pm 0.44^{* * *}$ & $0.78 \pm 0.46^{* * *}$ & $<.0001$ \\
\hline Mental fatigue (total score): & $5.52 \pm 1.33$ & $5.38 \pm 1.12$ & $5.41 \pm 1.08$ & $5.29 \pm 1.24$ & $3.59 \pm 1.04^{* * *}$ & $3.37 \pm 1.07^{* * *}$ & $<.0001$ \\
\hline 8. Do you have difficulties concentrating? & $1.43 \pm 0.53$ & $1.40 \pm 0.49$ & $1.42 \pm 0.50$ & $1.33 \pm 0.51$ & $0.74 \pm 0.52^{* * *}$ & $0.71 \pm 0.53^{* * *}$ & $<.0001$ \\
\hline $\begin{array}{l}\text { 9. Do you make slips of the tongue when } \\
\text { speaking? }\end{array}$ & $1.16 \pm 0.41$ & $1.14 \pm 0.40$ & $1.17 \pm 0.38$ & $1.19 \pm 0.51$ & $0.91 \pm 0.34^{* * *}$ & $0.88 \pm 0.38^{* * *}$ & $<.0001$ \\
\hline $\begin{array}{l}\text { 10. Do you find it more difficult to find the } \\
\text { correct word? }\end{array}$ & $1.24 \pm 0.47$ & $1.22 \pm 0.42$ & $1.20 \pm 0.41$ & $1.21 \pm 0.52$ & $0.95 \pm 0.22^{* * *}$ & $0.93 \pm 0.25^{* * *}$ & $<.0001$ \\
\hline 11. How is your memory? & $1.69 \pm 0.54$ & $1.62 \pm 0.52$ & $1.61 \pm 0.49$ & $1.57 \pm 0.62$ & $0.98 \pm 0.58^{* * *}$ & $0.85 \pm 0.61^{* * *}$ & $<.0001$ \\
\hline
\end{tabular}

Data are mean \pm SD. Product effect was evaluated by analysis of covariance (ANCOVA). Post-hoc test with Bonferroni adjustment was applied to variables with significant group difference for further pair-wise group comparison at day 60 . ${ }^{* * *} P<0.001$ compared with placebo group, ${ }^{\# \# ~} P<0.01$ compared with low dose group.

Table 4. Group differences in the scores of quality of life (QOL) questionnaire 


\begin{tabular}{|c|c|c|c|c|c|c|c|}
\hline & \multicolumn{3}{|c|}{ Baseline } & \multicolumn{3}{|c|}{ Day 60} & \multirow{2}{*}{$\begin{array}{c}\text { Product } \\
\text { effect } \\
p- \\
\text { value }\end{array}$} \\
\hline & $\begin{array}{l}\text { Placebo } \\
(\mathrm{n}=58)\end{array}$ & $\begin{array}{l}\text { Low } \\
\text { dose } \\
(n=58)\end{array}$ & $\begin{array}{l}\text { High } \\
\text { dose } \\
(\mathrm{n}=59)\end{array}$ & $\begin{array}{l}\text { Placebo } \\
(\mathrm{n}=58)\end{array}$ & $\begin{array}{l}\text { Low } \\
\text { dose } \\
(n=58)\end{array}$ & $\begin{array}{l}\text { High dose } \\
\qquad(\mathrm{n}=59)\end{array}$ & \\
\hline 1. How would you rate your quality of life? & $3.4 \pm 0.6$ & $3.4 \pm 0.6$ & $3.4 \pm 0.6$ & $3.4 \pm 0.5$ & $3.7 \pm 0.5^{*}$ & $3.8 \pm 0.5^{* * *}$ & 0.0021 \\
\hline 2. How satisfied are you with your health? & $3.3 \pm 0.7$ & $3.2 \pm 0.7$ & $3.3 \pm 0.6$ & $3.2 \pm 0.6$ & $3.6 \pm 0.6^{* * *}$ & $3.7 \pm 0.6^{* * *}$ & $<.0001$ \\
\hline Physics (PHYS area score): & $48.8 \pm 8.4$ & $49.2 \pm 7.4$ & $48.1 \pm 8.4$ & $49.1 \pm 7.3$ & $52.6 \pm 7.5^{*}$ & $53.8 \pm 8.6^{* * *}$ & 0.0024 \\
\hline $\begin{array}{l}\text { 3. To what extent do you feel that physical pain } \\
\text { prevents you from doing what you need to do? }\end{array}$ & $2.1 \pm 0.8$ & $2.1 \pm 0.7$ & $2.1 \pm 0.9$ & $2.2 \pm 0.9$ & $1.8 \pm 0.9^{*}$ & $1.7 \pm 0.8^{* *}$ & 0.0034 \\
\hline $\begin{array}{l}\text { 4. How much do you need any medical treatment to } \\
\text { function in your daily life? }\end{array}$ & $1.7 \pm 0.8$ & $1.8 \pm 0.9$ & $1.6 \pm 0.9$ & $1.6 \pm 0.9$ & $1.6 \pm 1.0$ & $1.7 \pm 1.0$ & 0.8198 \\
\hline 10. Do you have enough energy for everyday life? & $3.2 \pm 0.7$ & $3.2 \pm 0.7$ & $3.1 \pm 0.7$ & $3.2 \pm 0.7$ & $3.5 \pm 0.7^{*}$ & $3.6 \pm 0.6^{* *}$ & 0.0034 \\
\hline 15. How well are you able to get around? & $3.6 \pm 0.6$ & $3.6 \pm 0.6$ & $3.6 \pm 0.7$ & $3.6 \pm 0.5$ & $3.7 \pm 0.6$ & $3.8 \pm 0.6$ & 0.1882 \\
\hline 16. How satisfied are you with your sleep? & $3.0 \pm 0.7$ & $2.9 \pm 0.9$ & $2.9 \pm 0.8$ & $3.1 \pm 0.7$ & $3.6 \pm 0.8^{* * *}$ & $3.8 \pm 0.7^{* * *}$ & $<.0001$ \\
\hline $\begin{array}{l}\text { 17. How satisfied are you with your ability to perform } \\
\text { your daily living activities? }\end{array}$ & $3.5 \pm 0.6$ & $3.6 \pm 0.7$ & $3.5 \pm 0.6$ & $3.4 \pm 0.6$ & $3.8 \pm 0.5^{* *}$ & $3.8 \pm 0.5^{* * *}$ & 0.0007 \\
\hline $\begin{array}{l}\text { 18. How satisfied are you with your capacity for } \\
\text { work? }\end{array}$ & $3.6 \pm 0.6$ & $3.6 \pm 0.6$ & $3.6 \pm 0.6$ & $3.6 \pm 0.6$ & $3.7 \pm 0.5$ & $3.7 \pm 0.5$ & 0.2374 \\
\hline Psychology (PSYCH area score): & $54.0 \pm 10.2$ & $54.0 \pm 10.1$ & $54.3 \pm 9.5$ & $56.3 \pm 8.8$ & $57.3 \pm 8.5$ & $57.8 \pm 8.0$ & 0.4383 \\
\hline 5. How much do you enjoy life? & $3.3 \pm 0.7$ & $3.3 \pm 0.9$ & $3.3 \pm 0.8$ & $3.3 \pm 0.6$ & $3.5 \pm 0.6$ & $3.6 \pm 0.5$ & 0.0536 \\
\hline $\begin{array}{l}\text { 6. To what extent do you feel your life to be } \\
\text { meaningful? }\end{array}$ & $3.4 \pm 0.8$ & $3.4 \pm 0.8$ & $3.4 \pm 0.7$ & $3.6 \pm 0.6$ & $3.6 \pm 0.6$ & $3.6 \pm 0.5$ & 0.8199 \\
\hline 7. How well are you able to concentrate? & $3.0 \pm 0.8$ & $3.0 \pm 0.7$ & $3.0 \pm 0.7$ & $3.1 \pm 0.7$ & $3.4 \pm 0.7^{* *}$ & $3.5 \pm 0.7^{* * *}$ & 0.0004 \\
\hline 11. Are you able to accept your bodily appearance? & $3.4 \pm 0.6$ & $3.4 \pm 0.5$ & $3.4 \pm 0.7$ & $3.5 \pm 0.6$ & $3.6 \pm 0.6$ & $3.6 \pm 0.6$ & 0.8489 \\
\hline 19. How satisfied are you with yourself? & $3.6 \pm 0.6$ & $3.6 \pm 0.6$ & $3.6 \pm 0.6$ & $3.6 \pm 0.6$ & $3.7 \pm 0.5$ & $3.7 \pm 0.5$ & 0.3861 \\
\hline $\begin{array}{l}\text { 26. How often do you have negative feelings, such as } \\
\text { blue mood, despair, anxiety, depression? }\end{array}$ & $2.3 \pm 0.7$ & $2.3 \pm 0.7$ & $2.3 \pm 0.8$ & $2.4 \pm 0.5$ & $2.0 \pm 0.5^{* * *}$ & $1.9 \pm 0.5^{* * *}$ & $<.0001$ \\
\hline Social (SOCIL area score): & $59.6 \pm 11.0$ & $58.8 \pm 13.1$ & $59.7 \pm 10.8$ & $60.9 \pm 10.9$ & $64.2 \pm 10.9$ & $65.1 \pm 9.1$ & 0.0654 \\
\hline $\begin{array}{l}\text { 20. How satisfied are you with your personal } \\
\text { relationships? }\end{array}$ & $3.6 \pm 0.6$ & $3.6 \pm 0.6$ & $3.6 \pm 0.6$ & $3.6 \pm 0.6$ & $3.7 \pm 0.5$ & $3.6 \pm 0.6$ & 0.8873 \\
\hline $\begin{array}{l}\text { 21. How satisfied are you with the support you get } \\
\text { from your friends? }\end{array}$ & $3.1 \pm 0.8$ & $3.0 \pm 0.7$ & $3.0 \pm 0.8$ & $3.2 \pm 0.7$ & $3.5 \pm 0.7^{* *}$ & $3.6 \pm 0.6^{* * *}$ & 0.0004 \\
\hline $\begin{array}{l}\text { 22. How satisfied are you with your performance at the } \\
\text { party? }\end{array}$ & $3.5 \pm 0.5$ & $3.5 \pm 0.6$ & $3.6 \pm 0.6$ & $3.6 \pm 0.5$ & $3.6 \pm 0.6$ & $3.6 \pm 0.5$ & 0.9989 \\
\hline Environment (ENVIR area score): & $54.7 \pm 11.2$ & $54.6 \pm 11.4$ & $54.6 \pm 11.3$ & $55.5 \pm 7.2$ & $56.0 \pm 8.4$ & $56.1 \pm 9.9$ & 0.9055 \\
\hline 8. How safe do you feel in your daily life? & $3.1 \pm 0.7$ & $3.2 \pm 0.7$ & $3.2 \pm 0.7$ & $3.2 \pm 0.5$ & $3.2 \pm 0.5$ & $3.3 \pm 0.7$ & 0.7612 \\
\hline 9. How healthy is your physical environment? & $2.9 \pm 0.8$ & $2.9 \pm 0.8$ & $2.9 \pm 0.7$ & $3.1 \pm 0.6$ & $3.1 \pm 0.7$ & $3.0 \pm 0.7$ & 0.9755 \\
\hline 12. Have you enough money to meet your needs? & $3.1 \pm 0.5$ & $3.2 \pm 0.9$ & $3.1 \pm 0.7$ & $3.2 \pm 0.8$ & $3.2 \pm 0.8$ & $3.2 \pm 0.7$ & 0.9768 \\
\hline 13. How available to you is the information that you & $3.3 \pm 0.6$ & $3.3 \pm 0.6$ & $3.3 \pm 0.6$ & $3.3 \pm 0.5$ & $3.3 \pm 0.6$ & $3.3 \pm 0.6$ & 0.8769 \\
\hline
\end{tabular}

need in your day-to-day life? 


\begin{tabular}{|c|c|c|c|c|c|c|c|}
\hline & \multicolumn{3}{|c|}{ Baseline } & \multicolumn{3}{|c|}{ Day 60} & \multirow{2}{*}{$\begin{array}{c}\text { Product } \\
\text { effect } \\
p- \\
\text { value }\end{array}$} \\
\hline & $\begin{array}{l}\text { Placebo } \\
(\mathrm{n}=58)\end{array}$ & $\begin{array}{l}\text { Low } \\
\text { dose } \\
(n=58)\end{array}$ & $\begin{array}{l}\text { High } \\
\text { dose } \\
(\mathrm{n}=59)\end{array}$ & $\begin{array}{l}\text { Placebo } \\
(\mathrm{n}=58)\end{array}$ & $\begin{array}{l}\text { Low } \\
\text { dose } \\
(\mathrm{n}=58)\end{array}$ & $\begin{array}{l}\text { High dose } \\
\qquad(\mathrm{n}=59)\end{array}$ & \\
\hline $\begin{array}{l}\text { 14. To what extent do you have the opportunity for } \\
\text { leisure activities? }\end{array}$ & $3.2 \pm 0.9$ & $3.2 \pm 0.8$ & $3.1 \pm 0.9$ & $3.2 \pm 0.8$ & $3.2 \pm 0.8$ & $3.2 \pm 0.8$ & 0.8395 \\
\hline $\begin{array}{l}\text { 23. How satisfied are you with the conditions of your } \\
\text { living place? }\end{array}$ & $3.3 \pm 0.7$ & $3.3 \pm 0.7$ & $3.3 \pm 0.7$ & $3.3 \pm 0.6$ & $3.3 \pm 0.5$ & $3.3 \pm 0.5$ & 0.9487 \\
\hline $\begin{array}{l}\text { 24. How satisfied are you with your access to health } \\
\text { service? }\end{array}$ & $3.2 \pm 0.6$ & $3.2 \pm 0.7$ & $3.2 \pm 0.7$ & $3.2 \pm 0.5$ & $3.3 \pm 0.6$ & $3.3 \pm 0.7$ & 0.8256 \\
\hline 25. How satisfied are you with your transport? & $3.3 \pm 0.5$ & $3.3 \pm 0.6$ & $3.3 \pm 0.7$ & $3.3 \pm 0.5$ & $3.3 \pm 0.6$ & $3.3 \pm 0.6$ & 0.9248 \\
\hline
\end{tabular}

Data are mean \pm SD. Product effect was evaluated by ANCOVA. Post-hoc test with Bonferroni adjustment was applied to variables with significant group difference for further pair-wise group comparison at day $60 .{ }^{*} P<0.05,{ }^{* *} P<0.01,{ }^{* * *} P<0.001$ compared with placebo group.

The item score of Q3, Q4 and Q26 were reversed (calculated as 6 minus raw item score).

Table 5. Group differences in the scores of sexual life quality (SLQ) questionnaire

\begin{tabular}{|c|c|c|c|c|c|c|c|c|}
\hline \multirow[b]{2}{*}{ Gender } & & \multicolumn{3}{|c|}{ Baseline } & \multicolumn{3}{|c|}{ Day 60} & \multirow{2}{*}{$\begin{array}{c}\text { Product } \\
\text { effect } \\
p \text {-value }\end{array}$} \\
\hline & & Placebo & Low & High & Placebo & Low dose & High dose & \\
\hline \multirow{12}{*}{ Male } & 1 Eremuncus l lovemaling & $128+2-3>0$ & $162+17 ?$ & $124+146$ & & & & C00001 \\
\hline & 2 Duration of lovemaking & $429+150$ & $421+105$ & $393+111$ & $487+113$ & $639+140^{* * *}$ & $621+120^{* * *}$ & $<00001$ \\
\hline & 3. Ease of insertion & $48.2 \pm 11.1$ & $49.5 \pm 11.2$ & $48.7 \pm 12.4$ & $52.2 \pm 14.6$ & $60.6 \pm 12.4^{*}$ & $60.7 \pm 10.0^{* *}$ & 0.0106 \\
\hline & 4. Ease of achieving orgasm & $49.6 \pm 14.6$ & $50.0 \pm 17.3$ & $47.8 \pm 15.6$ & $53.0 \pm 13.6$ & $62.0 \pm 13.6^{*}$ & $62.9 \pm 14.2^{* *}$ & 0.0150 \\
\hline & 5. Ease of initiating lovemaking & $52.2 \pm 13.2$ & $51.4 \pm 20.0$ & $49.6 \pm 15.4$ & $52.2 \pm 11.1$ & $64.4 \pm 15.0^{* * *}$ & $62.9 \pm 11.0^{* * *}$ & $<0.0001$ \\
\hline & 6. Pleasure of anticipation & $50.0 \pm 9.0$ & $51.4 \pm 17.8$ & $52.2 \pm 15.2$ & $47.8 \pm 13.8$ & $63.0 \pm 14.1^{* * *}$ & $68.3 \pm 13.8^{* * *}$ & $<0.0001$ \\
\hline & 7. Carefree feelings during lovemaking & $46.9 \pm 11.1$ & $45.8 \pm 15.5$ & $46.0 \pm 10.8$ & $53.9 \pm 12.5$ & $66.7 \pm 15.9^{* *}$ & $66.1 \pm 13.1^{* *}$ & 0.0013 \\
\hline & 8. Pleasure of orgasm & $42.4 \pm 10.9$ & $39.4 \pm 17.6$ & $38.8 \pm 12.9$ & $50.0 \pm 14.9$ & $61.6 \pm 14.7^{* *}$ & $62.1 \pm 12.9^{* *}$ & 0.0018 \\
\hline & 9. Overall pleasure of lovemaking & $43.8 \pm 11.0$ & $43.5 \pm 18.1$ & $42.0 \pm 13.3$ & $52.2 \pm 13.0$ & $63.0 \pm 16.4^{* *}$ & $63.4 \pm 13.6^{* *}$ & 0.0065 \\
\hline & 10. Partner's overall pleasure of & $46.9 \pm 10.0$ & $47.2 \pm 17.1$ & $46.0 \pm 11.3$ & $52.6 \pm 12.2$ & $59.7 \pm 14.8^{*}$ & $60.7 \pm 12.1^{*}$ & 0.0348 \\
\hline & lovemaking & & & & & & & \\
\hline & SLQ scale score (mean of item 1-10) & $46.7 \pm 8.3$ & $46.7 \pm 12.1$ & $45.3 \pm 10.3$ & $50.9 \pm 9.9$ & $62.5 \pm 12.3^{* * *}$ & $63.3 \pm 10.4^{* * *}$ & $<0.0001$ \\
\hline \multirow[t]{12}{*}{ Female } & 1. Frequency of lovemaking & $38.4 \pm 19.8$ & $36.3 \pm 14.1$ & $40.7 \pm 17.7$ & $36.5 \pm 16.1$ & $52.8 \pm 15.2^{* * *}$ & $63.4 \pm 16.0^{* * *}$ & $<0.0001$ \\
\hline & 2. Duration of lovemaking & $45.1 \pm 21.1$ & $43.3 \pm 12.6$ & $46.8 \pm 18.0$ & $47.0 \pm 18.8$ & $56.0 \pm 19.4^{*}$ & $61.2 \pm 17.8^{* *}$ & $<0.0001$ \\
\hline & 3. Ease of insertion & $46.4 \pm 18.9$ & $44.6 \pm 9.7$ & $46.8 \pm 16.1$ & $50.5 \pm 18.2$ & $57.4 \pm 16.4$ & $58.2 \pm 16.8$ & 0.0909 \\
\hline & 4. Ease of achieving orgasm & $38.8 \pm 17.8$ & $40.0 \pm 13.3$ & $42.3 \pm 13.2$ & $42.0 \pm 18.4$ & $52.3 \pm 15.1^{*}$ & $53.9 \pm 15.0^{*}$ & 0.0240 \\
\hline & 5. Ease of initiating lovemaking & $42.0 \pm 17.1$ & $42.5 \pm 13.0$ & $44.0 \pm 13.6$ & $46.5 \pm 16.7$ & $56.0 \pm 17.5$ & $64.7 \pm 19.8^{* * *}$ & 0.0003 \\
\hline & 6. Pleasure of anticipation & $49.1 \pm 13.6$ & $47.5 \pm 10.1$ & $46.4 \pm 14.1$ & $50.5 \pm 16.3$ & $52.8 \pm 12.7$ & $62.5 \pm 19.2^{* *}$ & 0.0042 \\
\hline & 7. Carefree feelings during lovemaking & $47.8 \pm 18.0$ & $47.1 \pm 11.7$ & $47.6 \pm 13.9$ & $50.5 \pm 15.9$ & $63.0 \pm 20.9^{* *}$ & $67.7 \pm 16.5^{* * *}$ & 0.0009 \\
\hline & 8. Pleasure of orgasm & $42.9 \pm 19.4$ & $44.2 \pm 13.8$ & $45.6 \pm 14.6$ & $42.5 \pm 14.9$ & $56.0 \pm 17.5^{* * *}$ & $59.5 \pm 13.2^{* * *}$ & $<0.0001$ \\
\hline & 9. Overall pleasure of lovemaking & $47.8 \pm 18.7$ & $46.7 \pm 10.9$ & $49.6 \pm 14.2$ & $49.5 \pm 14.2$ & $56.9 \pm 16.7^{*}$ & $59.1 \pm 15.3^{*}$ & 0.0372 \\
\hline & 10. Partner's overall pleasure of & $52.2 \pm 20.7$ & $50.8 \pm 9.2$ & $52.8 \pm 14.7$ & $52.5 \pm 12.5$ & $58.8 \pm 16.6$ & $59.1 \pm 17.3$ & 0.1797 \\
\hline & lovemaking & & & & & & & \\
\hline & SLQ scale score (mean of item 1-10) & $45.0 \pm 15.1$ & $44.3 \pm 7.5$ & $46.3 \pm 11.9$ & $46.8 \pm 12.8$ & $56.2 \pm 12.5^{* * *}$ & $60.9 \pm 12.7^{* * *}$ & $<0.0001$ \\
\hline
\end{tabular}

Data are mean \pm SD. Product effect was evaluated by ANCOVA with stratification of gender. Post-hoc test with Bonferroni adjustment was applied to variables with significant group difference for further pair-wise group comparisonat day $60 .{ }^{*} P<0.05,{ }^{* *} P<0.01$, ${ }^{* * *} P<0.001$ compared with 
placebo group.

Table 6. Group differences in blood biomarkers

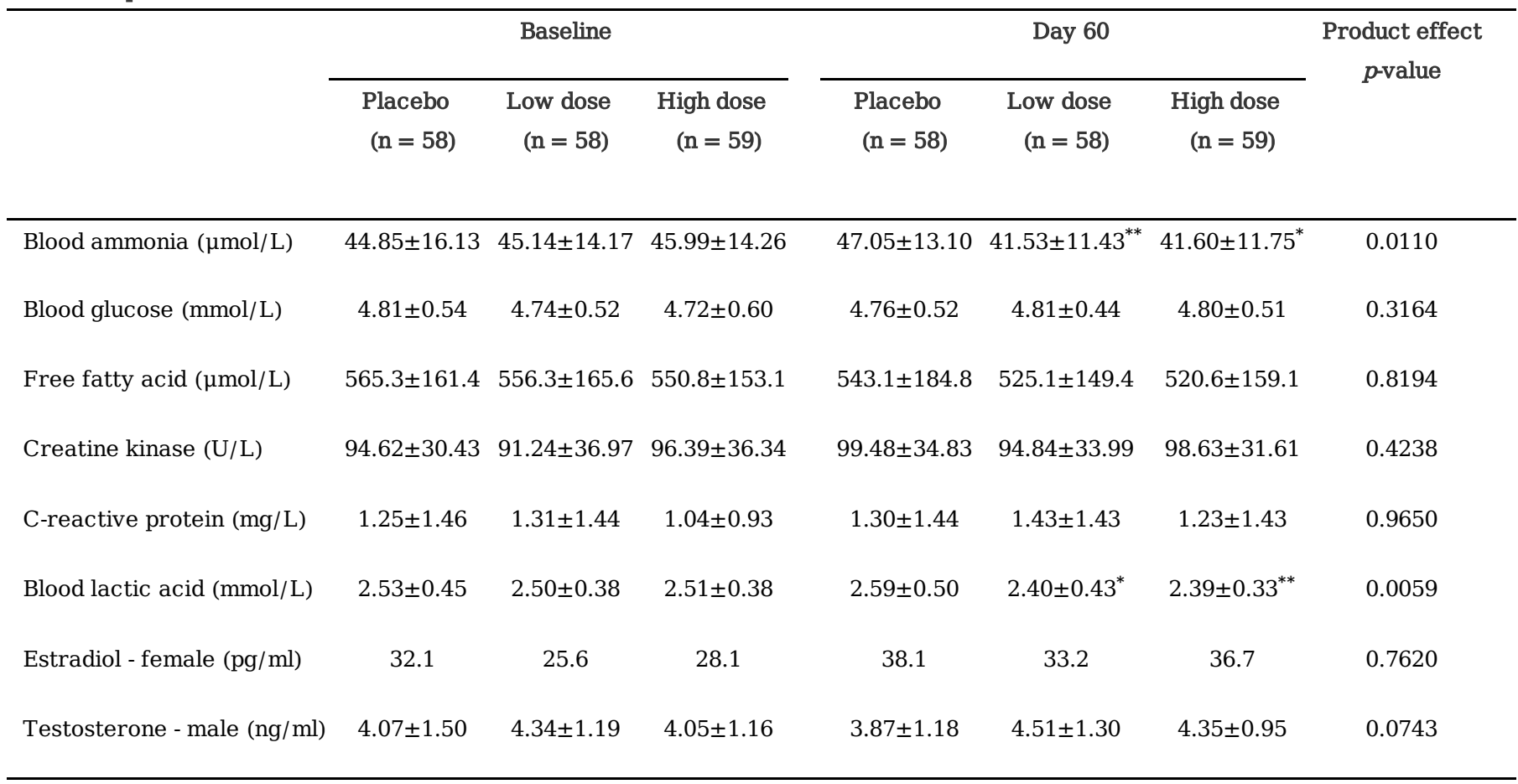

Data are mean \pm SD. Product effect was evaluated by ANCOVA. Post-hoc test with Bonferroni adjustment was applied to variables with significant group difference for further pair-wise group comparison at day $60 .{ }^{*} P<0.05,{ }^{* *} P<0.01$ compared with placebo group.

Estradiol concentration data was highly skewed. Median was reported and non-parametric method was used for group comparison.

Table 7. Univariate and multivariate associations between product effectiveness and the changes in blood biomarkers

\begin{tabular}{llllll}
\hline Covariates & \multicolumn{1}{l}{ Univariate } & & & Multivariate & \\
\cline { 2 - 3 } \cline { 5 - 6 } \cline { 5 - 6 } & OR $(95 \% \mathrm{CI})$ & $p$-value & & OR (95\% CI) & $p$-value \\
\hline Blood ammonia & $1.001(0.984-1.019)$ & 0.8654 & & $0.999(0.980-1.018)$ & 0.9272 \\
Blood glucose & $3.021(1.378-6.624)$ & 0.0058 & & $3.062(1.349-6.951)$ & 0.0075 \\
Free fatty acid & $1.000(0.998-1.002)$ & 0.8537 & & $1.000(0.998-1.002)$ & 0.8503 \\
Creatine kinase & $1.002(0.988-1.017)$ & 0.7376 & & $1.006(0.991-1.021)$ & 0.4467 \\
C-reactive protein & $0.846(0.610-1.175)$ & 0.3173 & & $0.825(0.582-1.171)$ & 0.2820 \\
Blood lactic acid & $0.313(0.136-0.717)$ & 0.0061 & & $0.334(0.144-0.776)$ & 0.0108 \\
Estradiol (female) & $1.001(0.994-1.007)$ & 0.8276 & & N/A & N/A \\
Testosterone (male) & $1.188(0.801-1.764)$ & 0.3916 & & N/A & N/A \\
\hline
\end{tabular}

Logistic regression was used to evaluate the associations between product effectiveness (cured and relieved) and the changes in blood biomarkers after the intervention. OR, odds ratio; CI, confidence interval; N/A, not applicable.

\section{Figures}




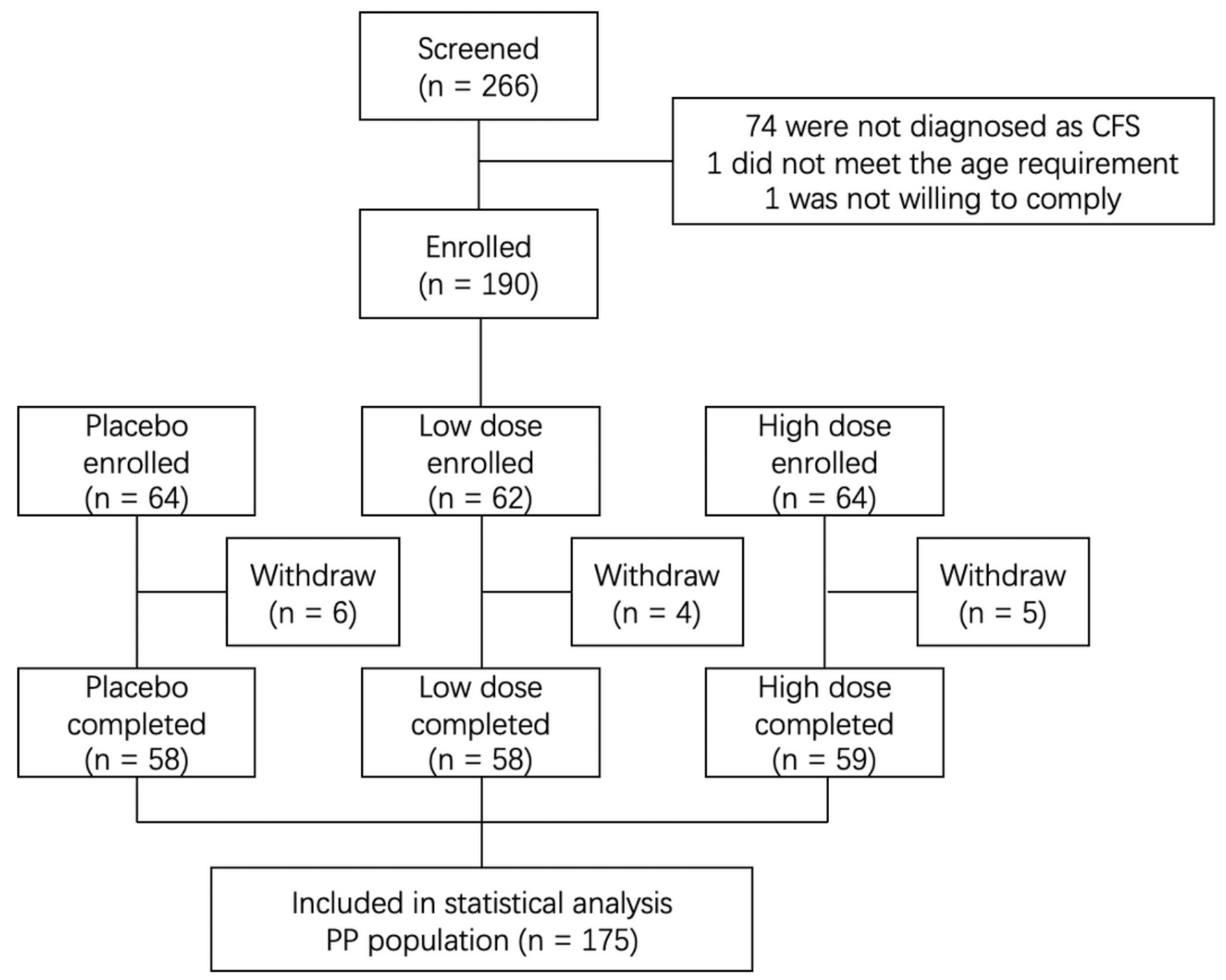

Figure 1

Flowchart of the clinical trial

\section{Supplementary Files}

This is a list of supplementary files associated with this preprint. Click to download.

- Supplementarymaterials.docx

- Supplementarymaterials.docx 